\title{
Immiserizing Credit: Challenging the Efficacy of Microfinance
}

\author{
Frank Raymond ${ }^{1}$, John Adams ${ }^{2}$ \\ ${ }^{1}$ Department of Economics and Finance, Bellarmine University, Louisville, USA \\ ${ }^{2}$ Center for Asian Studies, University of Virginia, Charlottesville, USA \\ Email: fraymond@bellarmine.edu
}

Received May 10, 2013; revised June 10, 2013; accepted July 10, 2013

Copyright (C) 2013 Frank Raymond, John Adams. This is an open access article distributed under the Creative Commons Attribution License, which permits unrestricted use, distribution, and reproduction in any medium, provided the original work is properly cited.

\begin{abstract}
Despite a dearth of theoretical studies, there is widespread perception that microfinance is an enormously useful tool for economic development. However, an increasing number of households in lesser developed countries are facing the same debt squeeze as those in the developed world, but are less able to manage debt responsibilities. The consequences are much more dramatic for LDC households because a much larger portion of household income is necessary for subsistence. As such, microfinance can become immiserizing for poor families with few assets. We develop a dynamic model that allows households to use credit markets in order to augment household consumption or capital. Results indicate a proclivity for households to increase debt over time, challenging the efficacy of microfinance as a sustainable tool for development.
\end{abstract}

Keywords: Economic Development; Microfinance; Household Consumption; Credit Markets

\section{Introduction}

For over three decades, billion dollars have been allocated by governments, multilateral agencies, and bilateral donors to microcredit and microfinance programs. In the present discussion, we are not going to get entangled in definitional issues. Suffice it to say that microcredit involves small loans, usually no more than $\$ 100$ or $\$ 200$ up to at most $\$ 1000$ to individuals belonging to groups designated by labels such as "the poorest of the poor" or "small farmers". Microfinance is a wider notion that includes savings options and sometimes crop, livestock, or credit insurance schemes. The goals of these programs are multiple and overlapping (Adams, Brunner \& Raymond [1]). Three of the most relevant goals are:

1) To raise personal, family, community, and national product;

2) To offer a formal alternative to such informal sources of loans as moneylenders and middlemen, with the hope of providing lower interest rates, and,

3) To empower disadvantaged groups, usually poor women, and to raise their levels of dignity and self-esteem.

Despite the billions of dollars devoted to microfinance, interventions in a myriad of examples around the world, the entire enterprise suffers from four flaws. First, at the design phase, there has been astonishingly little work done on the micro-foundations of the key institutions: the family farmers and small business entrepreneurs comprise the demand side of the market, the organization of the banking institutions, and the nature of the existing markets for small loans into which microfinance is being introduced. Economists are interested in information problems, incentives and the range of New Institutional Economic topics have not shown much interest in microfinance.

Second, because of the multiple and often fuzzy goals and gains that are allegedly inherent in these operations, it is frequently very difficult to appraise outcomes on a single yardstick such as profitability, efficiency, or welfare. Third, rigorous ex post economic and social accounting is rarely applied; indeed, many evaluations rely heavily on the sociological motif of asking the clients open-ended questions about whether they feel more empowered or are more able to confront the males of the household and so on. Fourth, when fairly rigorous ex post appraisals have been conducted, they show by a margin of roughly 9:1 at best that the specific projects are unable to sustain loan recoveries, teetering on the brink of insolvency if they have not failed already, or require a high level of continuing subsidies. Failures are many; successes are sparse (Chen and Dunn [2] and 
Yaron [3]).

It is our intention here to lay out the beginnings of a model of a peasant household that can serve to answer a simple but fundamental query: What are the conditions under which a rational borrower will accept credit and be able to apply it to a farm or business opportunity that will enable timely repayment and lay a foundation for a ratcheting upwards of family incomes, with a presumption of an overall social benefit? We have chosen to title the paper, "Immiserizing Credit", because we believe that these conditions are stringent, the bar is high, and the outcomes are often enough painful ${ }^{1}$. After all, if one begins with a family operating at the margin of subsistence, and then begins an attempt to uplift them economically and socially by putting them into debt, then the logical chain of events must be firmly reasoned and the outcomes statistically very likely; otherwise, the indebted clients will be worse off after two, three, or four rounds of annual cycles than they were at the beginning. The literature on microfinance is vast, but as we have stated, much of it is excessively descriptive, normative, and sanguine.

\section{Four Principles}

This research addresses household expenditures and rising debt in lesser developed countries. Traditional theories assert that microfinance is an important stimulus for economic development (Basu [4] and Robinson [5]). However, recent observations suggest that households in lesser developed countries are facing the same debt squeeze as the developed world, but are less able to manage debt responsibilities (Adams and Raymond [6]). The consequences are much more dramatic for LDC households because a much larger portion of household income is necessary for subsistence. Thus, for many poor peasant families, with little or no land or other assets, microfinance can become immiserizing. We develop a dynamic model that challenges current economic theory concerning the impact of microfinance on the poor.

The model is constructed around four basic principles. First, for LDC households, borrowing is severely constrained, in terms of both availability and overwhelming formal or informal terms of credit. Thus, borrowing is inadequate for entrepreneurship to succeed, but the debt is too much for households to live with. Second, perversely, the availability of credit increases household consumption and reduces the incentive for saving as a buffer. According to NLSS [7], 46.5 percent of borrowing by Nepalese households was used to augment consumption. Third, the tradeoff between time devoted towards human capital or labor influences household's abi-

\footnotetext{
${ }^{1}$ Fortunately or not, governments frequently resolve mass failures by canceling arrears in order to dampen unrest or garner electoral support. Of course, the belief that loans do not have to be repaid does little to create an appropriate banking culture.
}

lity to make good decisions concerning credit risk. Limited or asymmetric educational opportunities (as with women) increase the likelihood of poor credit management. Furthermore, poor credit decisions by parents increase the likelihood that children will be forced to leave school in order to supplement current income, reducing the ability of the next generation to effectively manage credit. This creates an intergenerational immiserizing cycle. Finally, risk (price, weather, pests) and imperfect information (best crop practices, illness, changing credit terms) are much more hazardous for LDC households, thus exacerbating the problem. We assume that households follow the conceptual model postulated by Dunn [8]. Figure 1 is a simple characterization of household debt management. This preliminary model incorporates credit availability, human capital (information) and production in order to illustrate household debt management. From this one can envision circumstances in which credit could enhance household wealth, and when it could become immiserizing.

\section{Linking Information and Credit with Household Production}

Households are engaged in the production of a typical capital-consumption good, $Y_{t}=F\left(L_{t}, K_{t}\right)$ requiring labor and capital inputs. We assume that this production function is second order continuous and that the marginal products are positive. Output can be consumed (or sold) $\left(C_{t}\right)$, or invested $\left(\Delta K_{t}\right)$ in future production. Assuming that markets function properly, on the margin house

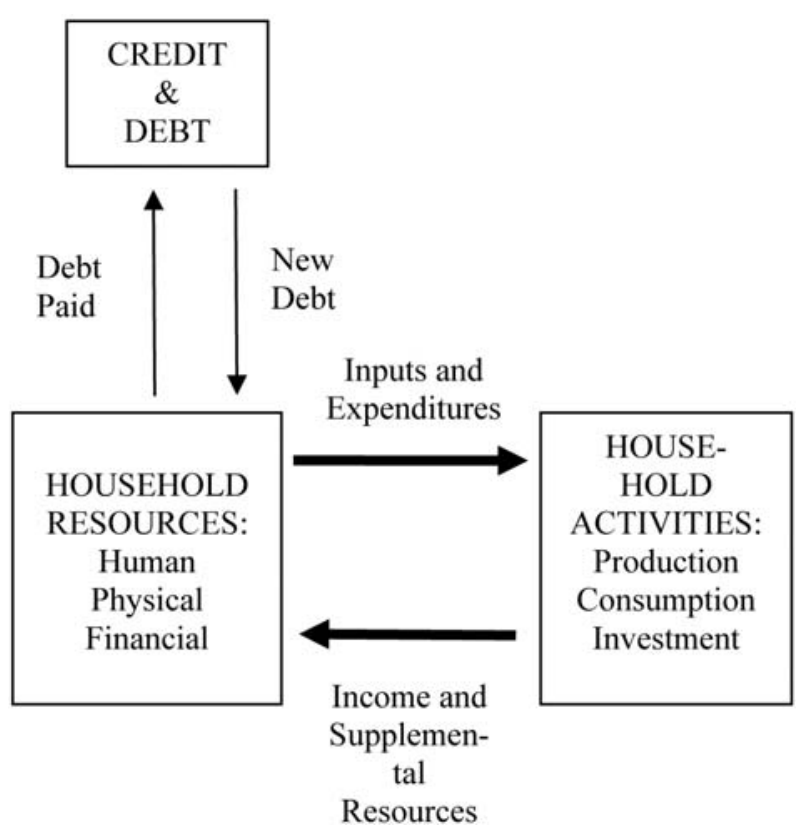

Figure 1. Household debt management depends upon the flow of funds generated by the resources and activities of the household. 
holds derive the same benefit whether a unit of the good is consumed or sold. Though this product need not be an agricultural good, in the developing world, this is often the case. Each period, households have the opportunity to augment either consumption or capital (or both) by borrowing, $B_{t}$. The source of funds may be formal or informal [1]. For simplification, we assume that borrowed funds are immediately and costlessly converted into the capital-consumption good. For example, if the household is engaged in the production of wheat, it can sell or consume wheat, or save it for seed. In this case, borrowing implies the acquisition of additional wheat which can be used for consumption or physical capital augmentation.

Household utility in each period depends on household consumption and debt. Households must choose how to allocate their productive time toward labor or towards gathering information (herein the equivalent of augmenting human capital). With additional information there is a greater chance that the household will (1) be able to find the most advantageous loan opportunities and (2) more effectively use the loan to increase production. However, the task of gathering relevant information is formidable because (1) it is difficult for families in developing countries to manage all their responsibilities, (2) microfinance team leader-advisors are not well informed, and (3) productivity raising investments are hard to accomplish and sustain; bugs eat crops, cows die, and Maoists appear on the doorstep.

Labor $\left(L_{t}\right)$ is a necessary input for production. Households gather information $\left(H_{t}\right)$ from both formal and informal lenders as well as from interactions with other borrowers. We normalize, so that individuals must decide what proportion of productive time should be spent on labor and what proportion should be spent on gathering information, thereby increasing human capital. So, a worker's productive time can be spent by working or by gathering information, $L_{t}+H_{t}=1$. Though unique, this model incorporates human capital into production as in Lucas [9] and Romer [10]. However, herein the information that is gathered facilitates debt management and the long run viability of the household.

Each period, output is divided between consumption, the replacement of capital that is depreciating at a rate equal to $\zeta$, and savings,

$$
Y_{t}=C_{t}+\zeta K_{t}+\dot{K}_{t} .
$$

When borrowing $\left(B_{t}\right)$ occurs in period $t$, it is assumed that a proportion of it is invested in supplementing capital (investment) and the remaining portion is devoted to supplementing income (for consumption or debt payments). Moreover, the proportion of credit spent on new physical capital is influenced by the amount of information households obtain: $\mu_{t}=\mu_{t}\left(H_{t}\right)$. Thus, a proportion equal to $1-\mu_{t}$ is spent on consumption. We assume that as human capital increases, households will be more responsible. That is, they are more likely to borrow for investment purposes, $\frac{\mathrm{d} \mu_{t}}{\mathrm{~d} H_{t}} \geq 0$. Assuming a typical capital-consumption good, borrowing, $B_{t}$, increases capital by $\mu\left(H_{t}\right) B_{t}$, or simply $\mu_{t} B_{t}$ Therefore, if one assumes that the household borrows $B_{t}$, and allocates a percentage of what it borrows $\left(\mu_{t}\right.$ of $\left.B_{t}\right)$ towards physical capital enhancement, then by (1a) the aggregate change in capital is given by $\dot{K}_{t}$ where

$$
\dot{K}_{t}=Y_{t}-C_{t}-\zeta K_{t}+\mu_{t} B_{t} .
$$

Recalling that $L_{t}+H_{t}=1$, this can also be written as:

$$
\dot{K}_{t}=F\left(1-H_{t}, K_{t}\right)-C_{t}-\zeta K_{t}+\mu_{t} B_{t} .
$$

Household profit derived from production of the capital-consumption good is given by

$$
\Pi=p Y_{t}-r K-w L,
$$

where we assume the output price is the numeraire $(p=1)$. In LDCs, interest rates are higher and payment plans are of shorter duration than in developed countries. It is possible that the average interest rate $\left(i_{t}=i_{t}\left(H_{t}\right)\right)$ will also vary with information $\left(H_{t}\right)$ as households seek out new lenders (e.g.: formal or informal) with varying terms of credit. Since the household must service its existing debt, $X_{t}$, its budget constraint (suppressing $\left.H_{t}\right)$ is:

$$
\Pi_{t}+\left(1-\mu_{t}\right) B_{t}=C_{t}+i_{t} X_{t}+\gamma_{t} X_{t} .
$$

The left hand side of Equation (2) represents income and the right side represents expenditures. Note that $\left(1-\mu\left(H_{t}\right)\right) B_{t}$ supplements income and $i_{t}\left(H_{t}\right) X_{t}$ represents the interest payment in period $t$, relative to outstanding debt, $X_{t}$. Occasionally, these expressions may be expressed more simply as $\left(1-\mu_{t}\right) B_{t}$ and $i_{t} X_{t}$, respectively. We assume that $\frac{\mathrm{d} i}{\mathrm{~d} H}<0$. That is, gathering information should lead to lower interest payments and a lower minimum payment each period. Finally, we also allow for payments on the principle, $\gamma_{t} X_{t}$, where $0 \leq \gamma_{t} \leq 1$.

\section{Maximizing Household Utility}

Assume that household utility rises with consumption and declines with increasing debt. Household utility is defined by $u\left(C_{t}, X_{t}\right)$, where $u(\cdot)$ is differentiable and concave with respect to both arguments, with $\frac{\partial u}{\partial C}>0$ and $\frac{\partial u}{\partial X}<0$. Therefore, the representative household must solve the following dynamic problem: 


$$
\max _{B, H} \int_{0}^{\infty} \mathrm{e}^{-\beta t} u\left(C_{t}, X_{t}\right) \mathrm{d} t
$$

subject to two dynamic constraints,

$$
\begin{gathered}
\dot{X}_{t}=B_{t}-\left(i\left(H_{t}\right)+\gamma_{t}\right) X, \\
\dot{K}_{t}=F\left(1-H_{t}, K_{t}\right)-C_{t}-\zeta K_{t}+\mu_{t}\left(H_{t}\right) B_{t},
\end{gathered}
$$

and the budget constraint,

$$
\Pi_{t}+\left(1-\mu_{t}\right) B_{t}-C_{t}-\left(i\left(H_{t}\right)+\gamma_{t}\right) X_{t} \geq 0 .
$$

Taking time to collect information $\left(H_{t}\right)$ and borrowing $\left(B_{t}\right)$ are the household's control variables. Debt and capital are the state variables for this problem. Equation (6) represents the household's budget constraint. When the constraint is zero, all income from the household business, plus any borrowing to supplement income, is devoted to consumption and financing current debt. Note that when $\gamma_{t}=0$ the household is making the minimum payment on its debt. The term $\beta t$ is the rate of discount.

To solve the system, we formulate the following Hamiltonian',

$$
\begin{aligned}
\boldsymbol{H}= & \mathrm{e}^{-\beta t} u(C, X)-\lambda_{1}(B-(i(H)+\gamma) X) \\
& +\lambda_{2}(F(1-H, K)-C-\zeta K+\mu(H) B) .
\end{aligned}
$$

Differentiating with respect to the controls, one obtains,

$$
\begin{aligned}
\boldsymbol{H}_{B}= & \mathrm{e}^{-\beta t}\left(u_{X} X_{B}\right)-\lambda_{1}\left(1-i(H) X_{B}\right) \\
& +\lambda_{2}\left(F_{K} K_{B}-\zeta K_{B}+\mu(H)\right) \stackrel{\text { set }}{=} 0
\end{aligned},
$$

and

$$
\begin{gathered}
\boldsymbol{H}_{H}=\mathrm{e}^{-\beta t}\left(u_{X} X_{H}\right)-\lambda_{1}\left(-i(H) X_{H}-i_{H}(H) X\right) \\
+\lambda_{2}\left(\mu_{H}(H) B\right) \stackrel{\text { set }}{=} 0
\end{gathered}
$$

The multipliers are the shadow prices of debt and capital. Generally speaking, $\lambda_{1}$ is the marginal disutility of debt and $\lambda_{2}$ is the marginal utility of capital.

The costate (or adjoint) equations are

$$
\dot{\lambda}_{1}=-\boldsymbol{H}_{X}
$$

and

$$
\dot{\lambda}_{2}=-\boldsymbol{H}_{K},
$$

where

$$
\dot{\lambda}_{1}=-\boldsymbol{H}_{X}=-\left\{\mathrm{e}^{-\beta t} u_{X}+(i+\gamma) \lambda_{1}\right\}
$$

${ }^{2}$ We suppress the time variable and other arguments when convenient. We also adopt the conventional notation for derivatives, $\frac{\partial F}{\partial L} \equiv F_{L}, \frac{\partial F}{\partial L K} \equiv F_{L K} \quad$ etc. and

$$
\dot{\lambda}_{2}=-\boldsymbol{H}_{K}=\left\{\lambda_{2}\left(F_{K}-\zeta\right)\right\} .
$$

Equation (10) describes the change in the shadow price of debt over time.

The steady state for this system is marked by $\dot{\lambda}_{1}=0, \dot{\lambda}_{2}=0, \dot{X}=0$, and $\dot{K}=0$. From this, we derive the following results:

$$
\begin{gathered}
\dot{\lambda}_{1}=0 \Rightarrow \lambda_{1}=\frac{-\mathrm{e}^{-\beta t} u_{X}}{i+\gamma}>0, \\
\dot{\lambda}_{2}=0 \Rightarrow F_{K}=\zeta, \\
\dot{X}=0 \Rightarrow B=(i+\gamma) X,
\end{gathered}
$$

and

$$
\dot{K}=0 \Rightarrow F(1-H, K)+\mu(H) B=C+\zeta K .
$$

The first condition (12) is our immiserizing condition. It states that, for a given interest rate ( $i$ ) and supplemental payment rate $(\gamma)$, the shadow price (marginal valuation) of debt will be constant over time only if $\left|u_{X}\right|$ rises. That is, the marginal disutility of debt is rising. This is a consequence of increasing debt. Equations (13) and (15) are the usual steady state conditions for capital accumulation. In particular, (15) states that output plus borrowing for new capital must equal consumption plus depreciation. Because the focus is on the accumulation of capital (or savings), this condition need not consider that consumption is supplemented by borrowing by the amount $(1-\mu(H)) B$. Condition (14) indicates that steady state borrowing will be no more than what the household intends to pay back the next period; debt is constant in the steady state. Thus, together Conditions (12) and (14) suggest that debt is short term in nature. This is consistent with the evolution of credit markets. For example, in agriculture borrowing bridges disruptions in revenue due to drought, flooding, or other acts of God. Funds are borrowed one year and repaid the next, whenever possible.

Figure 2 uses a phase diagram to illustrate how debt

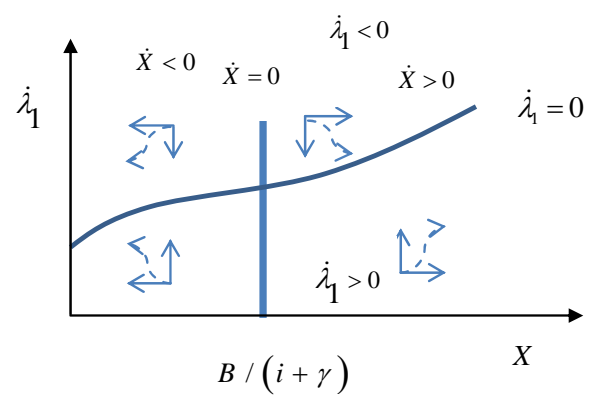

Figure 2. Prior to reaching steady state debt, households are motivated to cut that debt to zero. However, beyond the steady state level of debt, the tendency is to accumulate more debt. 
changes over time. From the diagram, it is clear that the steady state solution is not stable. The phase diagram indicates prior to reaching the steady state, the motivation is to reduce debt. Thus, in the event that exogenous forces prompt the accumulation of debt, the incentive is then to cut that debt to zero. However, if one moves beyond the steady state level of debt, $X_{s s}=B /(i+\gamma)$, the tendency is to accumulate more debt, therefore fulfilling our prediction that debt can be immiserizing.

Not only is there a tendency for debt to become a burden to households, but the debt burden increases the demand for additional debt, thus increasing the likelihood of default. This combination reduces the possibility for microfinance programs to sustain themselves over time.

\section{Conclusion}

In our dynamic model of household credit, there is no stable steady state solution. This solution is consistent with four basic principles which are not often considered. First, for poor households, borrowing is severely constrained; it is difficult to obtain and interest rates are high even among formal lenders. Second, despite the importance of savings for developing households, the availability of credit perversely reduces the incentive to save. Third, the poor tend to be poorly educated and less able to effectively manage credit. Moreover, unfortunate credit decisions by parents increase the likelihood that children will need to leave school. This creates an immiserizing intergenerational cycle. Finally, risk (price, weather, pests) and imperfect information (best crop practices, illness, changing credit terms) are much more hazardous for LDC households (Liu [11]).

We offer a model of microfinance which is unfettered by wishful thinking or political agendas. Prevailing thought suggests that microfinance can serve as a catalyst for growth, and in certain regions it appears that this has indeed been the case. However, microfinance has not always been sustainable, an important condition that differentiates it from subsidies, which can be both erratic and transitory. Common sense, as well as observations on the ground, suggests that many households in lesser developed countries are less equipped to manage even comparatively smaller debts due to the relative lack of discretionary income. Moreover, terms of credit and rules governing enforcement are far more subject to change. These circumstances can lead to an unmanageable burden with dire consequences for poor families.

As a result, microfinance can become immiserizing for poor families with their limited assets. This is precisely what our model demonstrates. To ensure responsible, reasonable outcomes, microfinance schemes should be carefully considered and properly regulated. Regulations concerning credit worthiness and terms of credit must be strictly enforced by local government or the NGOs responsible for the propagation of credit to the poor.

\section{Acknowledgements}

Dr. Adams was an insightful colleague and mentor. His passing has meant a tremendous loss to the field of development economics. The Center for Asian Studies at the University of Virginia was his most recent affiliation.

\section{REFERENCES}

[1] J. Adams, H. P. Brunner and F. Raymond, "Interactions of Informal and Formal Agents in South Asian Rural Credit Markets: An Analysis of Information Asymmetries and Adverse Selection with Heterogeneous Credit Services,” Review of Development Economics, Vol. 7, No. 3, 2003, pp. 431-444. doi:10.1111/1467-9361.00201

[2] M. A. Chen and E. Dunn, "Household Economic Portfolios,” USAID-AIMS, Washington DC, 1996.

[3] J. Yaron, "Rural Finance: Issues, Design, and Best Practices,” The World Bank, Washington DC, 1997.

[4] P. Basu, "Microfinance in India," Sage Publications, Los Angeles and London, 2008.

[5] M. S. Robinson, "The Microfinance Revolution: Sustainable Finance for the Poor,” The World Bank, Washington DC, 2001. doi:10.1596/0-8213-4524-9

[6] J. Adams and F. Raymond, "Did Yunus Deserve the Nobel Peace Prize, Microfinance or Macrofarce,” Journal of Economic Issues, Vol. 42, No. 2, 2008, pp. 435-444.

[7] Nepal Living Standards Survey (NLSS), "Central Bureau of Statistics, National Planning Commission Secretariat," His Majesty’s Government of Nepal, Vol. I \& II, 2004.

[8] E. Dunn, "Households, Microenterprises, and Debt," USAID-AIMS, Washington DC, 1996.

[9] R. E. Lucas, "On the Mechanics of Economic Growth," Journal of Monetary Economics, 1988, Vol. 22, No. 1, pp. 3-42. doi:10.1016/0304-3932(88)90168-7

[10] P. Romer, “Endogenous Technological Change,” Journal of Political Economy, Vol. 98, No. 5, 1990, pp. S71-S102. doi:10.1086/261725

[11] J. Liu, "Microfinance Risk Management with Work Breakdown Structure,” Journal of Financial Risk Management, Vol. 1, No. 3, 2012, pp. 38-41. doi:10.4236/jfrm.2012.13007 